\title{
Argument omissions in multiple German corpora
}

\section{Introduction}

In the past several decades, with the publication of results by Lehrer (1970), Mittwoch (1982), and Fellbaum and Kegl (1989), our understanding of the contextual factors that license null complements and constrain their interpretations - from constructions to genres to lexical classes - has vastly increased. As Fillmore (1986) made clear, null complementation, while motivated by such pragmatic drives as effort conservation, is linguistically constrained. As examples (1) and (2) show, semantically similar predicates differ in their ability to omit the presumably identical semantic role. ${ }^{1,2}$
(1) @jeb140
ah, ich
verstehe
ø. Gute arbeit!
@jeb140 ah,
understand
ø. Good job!
'ah, I \{understand\} ø. good job!'
* @jeb140 ah, I realize
'ah, I \{realize\} ø. good job!'
(2) *@jeb140 ah, ich realisiere
ø. Gute arbeit!
$\emptyset$ good job!

At the same time, the phenomenon is more systematic than an approach based on lexical idiosyncrasy might suggest. It is well known that certain constructions such as the passive or the imperative allow the omission of a verb's semantic 'deep subject' role (cf. [3]-[4]). But further constructions and contexts exist that can license omissions. Goldberg (2006: 196-197) argues that the discourse prominence of participants explains why constructions like the English experiential

1 For the convenience of the reader, I insert the symbol $ø$ in order to indicate 'missing' elements. The symbol is not to be taken as an empty element in the grammar.

2 A reviewer questioned whether realisieren had a sufficiently similar meaning to verstehen. The duden.de web-site lists a sense:

(in einem Prozess der Bewusstmachung) erkennen, einsehen, begreifen 'recognize, comprehend, understand something (in a process of becoming conscious of it)' (accessed on May 3, 2013).

Josef Ruppenhofer, Institute for the German Language, Mannheim/Germany, ruppenhofer@ ids-mannheim.de 
perfect license argument omissions such as (5) that may not occur in episodic contexts. And Ruppenhofer and Michaelis (2010) illustrated the effect of genre on omissibility, as in the case of product label statements such as (6).

(3) Eine Wasserader war zwar bereits gefunden $\emptyset$ a water vein was ineed already found $\varnothing$ 'Indeed, an underground water course has already been \{found\} ø...' (Passive)

(4) $\varnothing$ Zeig mir Deine Chromosomen, und ich sag Dir wer $\emptyset$ show me your chromosomes, and I tell you who Du bist. you are. ‘ø $\{$ Show $\}$ me your chromosomes, and I'll tell you who you are.' (Imperative)

(5) Dieser Mann ist eine Gefahr! Er hat schon eimmal $\emptyset$ getötet ... this man is a danger! He has already once $\emptyset$ killed ... 'This man is dangerous! He has $\{$ killed $\} \emptyset$ once before.'

(6) $\varnothing$ Unterstützt die Hautregeneration nach der Rasur. $\emptyset$ supports the skin's regeneration after the shave. 'ø $\{$ Supports\} the skin's regeneration after shaving.' (Labelese; found on deodorant)

At the same time certain conundrums remain. One is, if generalizations are possible for lexically licensed omissions, will they hold only for specific languages such as English or do they, at least to some extent, apply across languages? Another issue is how well any generalizations hold $u p$ in the face of data from attested language use given that much research into argument omission was based on introspection or constructed data. Related to the previous point, most work on argument omissions has, implicitly, if not explicitly, focused on some core types of written language, in particular texts found in newspapers. One may wonder if other types of written language, especially ones that represent other communicative settings, offer omission affordances that are not (commonly) found in the written texts that are most often investigated, or if they at least use these affordances in distinct ways.

The remainder of this paper is structured as follows. Section 2 provides a typology of argument omission. Section 3 describes the data sources, which are

3 http://www.blick.ch/news/ausland/auch-wir-wollen-die-wahrheit-wissen-id144800.html (Experiential perfect) 
used in this paper. Section 4 examines whether a generalization that Ruppenhofer (2004) proposed for English regarding the interpretation of omissions is plausible for German, too. In Section 5, I compare German data from social media and from spoken and written language to see how they differ in the omission types they admit, or at least in the frequency with which a given affordance is exploited. To this end, I will study the distributions of verb-initial constructions in the data as several of these involve argument omission. In section 6 , I focus on the analysis of various kinds of topic-drop sentences that can be observed in the social media data. In section 7 , I provide a discussion of the results and offer some conclusions.

\section{Overview of null instantiation}

Fillmore (1986) distinguishes lexically licensed omissions from constructionally licensed ones. With the former class, the argument-omission affordance is licensed by a particular lexical item, and nearly synonymous items may differ in omissibility of a given semantic role. The difference between verstehen ('understand') and realisieren ('realize') in examples (1) and (2) above illustrates lexical licensing.

With constructional omissions, it is the particular construction that determines the omissibility of a given argument, in a given syntactic role. For instance, von-phrase agents in passive predications can be omitted regardless of the lexical identity of the passive-form verb (cf. [3]). Likewise, all imperatives can omit their subjects, as in (4).

There also exist constructions that not only allow but actually require the omission of a verbal semantic role in the process of reconciling constructional and verbal requirements (Michaelis 2011: 269). For instance, some types of resultative constructions require omission of a theme argument under an existential interpretation. This is illustrated in examples (7) and (8), where no drink is specified but instead the resultative construction's own patient argument is provided.

(7) Die verschwundene Mutter war lustig gewesen und feierte the disappeared mother was funloving been and partied gern; gladly;

trank sich tot in zweiter Ehe ... drank herself dead in second marriage ... 'The mother who disappeared was fun-loving and liked to party; $\{$ drank $\}$ herself to death in her second marriage ...' 
(8) Aber Frau Professor konnte mich unter den Tisch trinken ... but Mrs Professor could me under the table drink ... 'But Madame Professor could \{drink\} me under the table ...' (deWaC)

Note that the omission-licensing constructions above are all general-language constructions. In addition to these, German also allows for genre-dependent omissions of the types discussed for English by Culy (1996), Bender (1999), and Ruppenhofer and Michaelis (2010). Sentence (9) illustrates the kind of object drop found in recipes; sentence (6) above is an instance of labelese.

(9) ø. 1-2 Tage darin marinieren.

ø. 1-2 days therein marinate.

' $\{$ Marinate $\} \emptyset$ in it for $1-2$ days' (Recipe object drop)

While I have so far considered cases where an argument can be optionally omitted, it is worth pointing out that there are lexical items that always suppress the expression of core participants of the event they encode. An example is the German verb zubeissen ('bite') in (10):

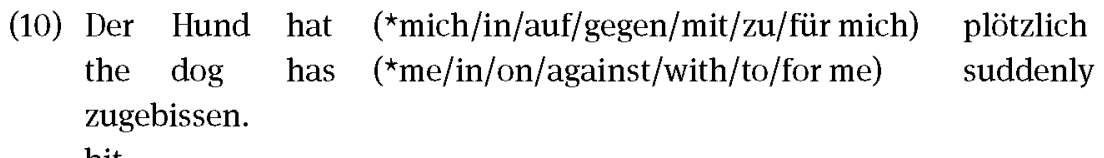

bit

'The dog suddenly $\{$ bit $\}[$ me].' (constructed)

A second major aspect of argument omissions is the interpretation that the omitted argument needs to receive. In some cases, unexpressed arguments are merely existentially bound, in others specific antecedents must be resolvable from the linguistic context (or co-text) or the speech setting. The parameter interpretation type is orthogonal to the licensing parameter. The passive construction allows for the omission of an existentially bound argument, as seen in (3), but so do lexical items like stricken ('knot') in (11). Similarly, the imperative licenses a definite omission of the addressee, shown in (4), but so does the lexical item verstehen ('understand') in (1).

(11) Es ist Juli, ich sollte lernen, aber ich stricke lieber It is July, I should study, but I knit rather

$\emptyset \quad$ \#Omatweet

$\emptyset \quad$ \#Omatweet

'It's July, I should be studying but I prefer \{knitting\} Ø. \#Omatweet' (Twitter) 
It is worth pointing out the differences between the typology introduced in the foregoing and the typology used, for instance, by Zifonun et al. (1997). Their category of ellipsis subsumes much, if not all, of what is discussed here and organizes it differently. Zifonun's (1997: 413-442) subtypes of ellipsis include the following:

- situational ellipsis: omitted referents are recoverable from the speech context (speaker, hearer, objects of joint attention, situations jointly observed)

- empratical ellipsis: predicates (usually) are missing that can be inferred based on the joint activity that speaker and hearer are engaged in

- phatic ellipsis: the speaker abandons their production, leaving it to the hearer to fill in the un-produced material

- structural ellipsis: omissions and ellipses licensed in specific text-types due to considerations of economy and condensation

Thus, unlike the notion of null instantiation, ellipsis encompasses cases of unexpressed predicates such as the example in (12):

(12) Hierher.

'(Over) here.' (instruction to furniture movers) (= Zifonun et al. 1997: 420)

In this study, I will only be concerned with argument omissions. I will not be specifically discussing whether they are, for instance, of the situational or the structural type in the sense of Zifonun et al. (1997), although this is clearly relevant for a detailed constructional analysis (Ruppenhofer and Michaelis 2010).

\section{Data}

I use several sources of data, as shown in Table 1. First, I use the Huge German Corpus (HGC) as my default corpus (Fitschen 2004). German examples in the text that bear no other identification of a source are taken from the HGC, which contains text from several German newspapers. I also use the deWaC German web-corpus (Baroni et al. 2009), which represents a wider range of written language. My third data set is a corpus of messages from the Twitter microblogging service, which exhibits some features of spoken language, despite being medially written. ${ }^{4}$ As discussed, for instance, by Richling (2008), social media data combines aspects of spoken and written language and exhibits a good degree of what Koch and Oesterreicher (1985) call conceptual orality, even if it is medially written.

4 The Twitter dataset cannot be redistributed due to Twitter's terms of service. 
Table 1: Corpora used.

\begin{tabular}{lrr}
\hline Corpus & Tokens & Units \\
\hline $\mathrm{HGC}$ & 204.813 .118 & $12.223 .281 \mathrm{~s}$ \\
deWaC & 1.627 .169 .557 & $92.395 .25 \mathrm{~s}$ \\
Twitter & 105.074 .399 & $7.311 .960 \mathrm{tw}$ \\
Bundestag & 5.756 .188 & $278.160 \mathrm{~s}$ \\
CallHome & 202.964 & $23.791 \mathrm{~s} / 19319 \mathrm{tu}$ \\
\hline
\end{tabular}

The fourth data set I work with is a corpus of parliamentary speeches from the German Bundestag. ${ }^{5}$ While the Bundestag data represents the spoken medium, it is conceptually more on the written end of the continuum between written and spoken language. The fifth and final data set are 80 transcripts from the CallHome German corpus, which contains telephone conversations between German students on exchange in the US and their family members or friends in Germany. ${ }^{6}$

A quantitative description of the corpora is given in Table 1. It should be noted that the units are not fully comparable across corpora. For Twitter, the unit is the individual tweet (tw) of up to 140 characters. For the CallHome corpus (Karins et al. 1997), I give two types of units, sentences (s) and turns (tu). For all other corpora, the unit is the sentence.

\section{Testing the generalization regarding interpretation type}

In this section I test Ruppenhofer's (2004) prediction that predicates in the same lexical class, defined in terms of FrameNet's frames, will omit a particular semantic role with the same interpretation type, if they can lexically license its omission at all. ${ }^{7}$ Ruppenhofer's prediction was tested on English but, given that Frame Semantics / FrameNet aims to provide a more or less language-independent analysis of lexical meanings, it was also meant to apply to other languages.

5 This data set was produced at the University of Stuttgart by Stefan Evert. An online version is available at http://linglit193.linglit.tu-darmstadt.de/CQP/Bundestag/frames-cqp.html. (last access: May 28, 2013).

6 The corpus has 100 transcripts but because of the effort required to pre-process the data to make it queryable, I used only 80 of them.

7 The prediction is not that all predicates in a particular lexical class will be able to omit a given semantic role. Clearly that would be untenable as, for instance, ankommen ('arrive') allows for an unrealized Frame Element Goal but erreichen ('reach') does not. 
FrameNet seeks to implement in lexicographical practice the concepts of Frame Semantics (Fillmore 1982, 1985). The basic idea is that many words are best understood as part of a group of terms that are connected to a particular type of situation and the participants and 'props' involved in it. The classes of events are the semantic frames. Lexical units (LUs) are said to evoke the frames. The roles associated with an event are referred to as frame elements (FEs). This system of analysis applies not only to events but also to relations and states; the frame-evoking expressions may be single words or multi-word expressions, which may belong to any syntactic category. For each LU, example sentences are extracted from corpus data and annotated with the frame elements, and their phrase types (PTs) and grammatical functions (GFs) vis-à-vis the target word. The goal of annotation is to exemplify every attested combination of FE, GF, and PT.

I consider data from two sources. The first source is the second release of the German Salsa project (Rehbein et al. 2012), which applied frame-semantic annotation to all instances of selected lemmas in a German newspaper corpus, re-using the English FrameNet's frames to the largest extent possible. Since the lemma coverage of Salsa is not as high as FrameNet's for English, I also took random samples for additional predicates from the HGC. For these samples, I manually sense-disambiguated 200 lemma instances of the target predicates and recorded for each instance exhibiting the frame of interest how the semantic role of interest was realized. If the role was overtly expressed, I recorded whether the semantic role was morpho-syntactically definite or indefinite. If it was unrealized, I recorded its interpretation type, anaphoric or existential. ${ }^{8}$

Table 2 shows the results of this preliminary study. ${ }^{9}$ The predicates marked with an asterisk are ones for which Salsa data was used. In the table, the row total for the predicates for which I took random samples is usually less than 200, the size of my random samples. The main reasons are polysemy (e.g. ankommen also has senses 'depend (on)' and 'go down well (with)'); misspellings (e.g. abreisen 'depart' instead of abreißen 'tear off'); and cases where a potential instance of a particle verb actually consists of the simple verb reisen 'travel' occurring with an unconnected instance of the particle or preposition $a b$ 'off'. (So as not to exclude cases where the particle occurred separate from the verb stem, the samples for particle verbs included not only cases where the two occurred together but also

8 For the purposes of the present study, as for Ruppenhofer (2004), the morpho-syntactic form of overt mentions serves as a proxy for their discourse status in accord with observations by Ariel (1988), Fraurud (1996), and Gundel et al. (1993) inter alia that the two are strongly correlated. 9 The Frame Create textile is not an existing FrameNet frame; I posit it here for convenience. 
Table 2: Morphosyntax of realizations of selected FEs in corpus data.

\begin{tabular}{|c|c|c|c|c|c|c|c|}
\hline Verb & Frame & $\mathrm{FE}$ & Def & Indef & Zero & NI-type & $\mathbf{N}$ \\
\hline ankommen ${ }^{\star}$ & Arriving & Goal & 5 & 2 & 5 & DNI & 12 \\
\hline eintreffen* & Arriving & Goal & 14 & 0 & 9 & DNI & 23 \\
\hline zurückkehren* & Arriving & Goal & 36 & 5 & 16 & DNI & 57 \\
\hline abreisen & Departing & Source & 25 & 2 & 137 & DNI & 164 \\
\hline abfahren & Departing & Source & 26 & 0 & 22 & DNI & 48 \\
\hline zustimmen* & Agreeing & Content & 43 & 23 & 5 & DNI & 74 \\
\hline einwilligen & Agreeing & Content & 67 & 30 & 53 & DNI & 150 \\
\hline Bruder* & Kinship & Ego & 29 & 0 & 8 & DNI & 44 \\
\hline Mutter* & Kinship & Ego & 17 & 6 & 17 & DNI & 44 \\
\hline Schwester* & Kinship & Ego & 5 & 0 & 2 & DNI & 19 \\
\hline Vater* & Kinship & Ego & 27 & 4 & 23 & DNI & 56 \\
\hline füllen & Filling & Theme & 10 & 60 & 63 & INI & 133 \\
\hline schmücken & Filling & Theme & 55 & 62 & 18 & INI & 135 \\
\hline sticken & Create textile & Product & 9 & 15 & 49 & INI & 170 \\
\hline stricken & Create textile & Product & 4 & 22 & 36 & INI & 62 \\
\hline häkeln & Create textile & Product & 2 & 23 & 23 & INI & 55 \\
\hline backen & Cooking creation & Produced food & 18 & 54 & 20 & INI & 92 \\
\hline kochen & Cooking creation & Produced food & 10 & 24 & 76 & INI & 110 \\
\hline
\end{tabular}

all cases where a sentence contained the simple verb and an instance of the particle anywhere in the sentence.)

As can be seen, the regularity observed for English also seems to hold for German predicates belonging to the same lexical class. For instance, abreisen ('depart'), abfliegen ('fly away/off'), abfahren ('drive away/off') all require anaphoric interpretation of uninstantiated Sources, while backen ('bake') and kochen ('cook') require existential interpretation of omitted Produced food FEs.

The data in Table 2 also are compatible with Ruppenhofer (2004)'s observation that the interpretation type for omitted instances seems to correlate with the information status of overt instances. That is, if an omissible FE's overt instances tend to be given, as indicated by morpho-syntactic definiteness, its interpretation under omission will be anaphoric, if they tend to be new, as indicated by morpho-syntactic indefiniteness, its interpretation under omission will be existential. This correlation holds for all the predicates in Table 2.

Both of these generalizations, at least in their strongest form, are open to falsification by inspection of additional data. Since there exist, however, a great many predicates with some kind of argument omission affordance, it is not possible to exhaustively test the predictions across all of the German vocabulary in the context of the current study. 


\section{Constructional omission affordances: verb-initial utterances in German}

In this section, I turn to the question whether social media data from Twitter differs from the classical written data found in newspaper corpora in the omission types that are found or the frequency with which different kinds of omissions occur. Since there are quite a few omission-licensing constructions that could be investigated, I focus on constructions that are verb-initial in order to keep the effort needed to identify the constructions under investigation manageable.

Word order in standard German is verb-second in finite main clauses and verb-final in finite subordinate clauses. Additionally, some verb-initial constructions exist. As discussed by Auer (1993: 195), one can subdivide these constructions according to whether the predicates realize all their core arguments or not. I begin by considering the first group, which Auer, following tradition, calls cases of proper V1 (eigentliche Verbspitzenstellung). The constructions of this type include some types of exclamatives (13); yes/no-questions (14); presentational constructions with a finite (typically, third-person) verb form such as (15), which are often found at the beginning of jokes; wenn (if)-less protases in conditional sentences (16); and what one may call contrast-inversions such as (17).

(13) Ist das schön.

Is that nice.

'Is that nice!'

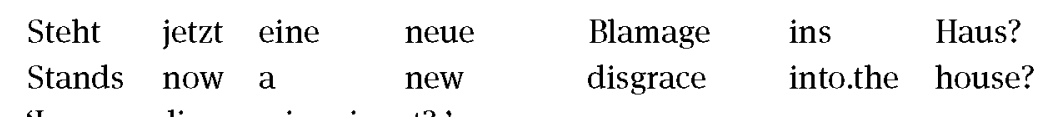

'Is a new disgrace imminent?'

(15) Kommt ein Mann zum

Comes a man to.the

habe ein Problem, alle

Psychiater: „Herr Doktor, ich

have a problem, everybody

psychiatrist: "Mr Doctor, I

„Der Nächste bitte.“

übersehen mich." -

"The next please."

A man comes to see a psychiatrist: "Doctor, I have a problem, everybody overlooks me." - "Next, please”.'

(16) Kommt ein Beschluß durch, der die Verpflichtung zur Comes a decision through, which the obligation to.the 
Offenbarung streicht, stehe ich nicht zur Verfügung. disclosure strikes, stand I not to.the disposal. 'If a resolution passes that eliminates the need for disclosure, then I won't serve/stand.'

(17) Es ist mit Sicherheit eine der heikelsten Sequenzen in It is with certainty one of.the most.delicate sequences in Sally Potters Film. Kann doch Orlandos Hingabe mißdeutet Sally Potter's film. Can though Orlandos devotion misinterpreted werden als Zugeständis an die einzig mögliche Utopie, der be as concession to the single possible utopia, that von Mann und Frau. of man and woman.

'It is certainly one of the most delicate sequences in Sally Potter's movie [given that/since] Orlando's devotion can be misinterpreted as a concession to the only possible utopia, that of man and woman. '

A verb-initial construction type that is uncommon in standard written German and which Auer does not discuss, but which can be found quite frequently on Twitter, are apodoses/consequent statements of conditional constructions such as (18)-(19), where the conditional protasis (wenn-clause) is unexpressed.

(18) Gehe ich halt ohne Hose los! Go I just without pants off!

'So then I'll just go off without pants' (Twitter)

(19) Dreh ich halt die \#Musik auf . \#1live \#gotye Turn I just the music up . \#1live \#gotye 'So then I'll just turn up the music.' (Twitter)

A further V1-construction-type is exemplified by cases where an expletive $d a$ seems to be omitted, as in (20).

(20) Und da sage ich so, Peter saß mir schräg And there say I so, Peter sat me diagonally gegenüber, sage ich so, du da Peter, da opposite, say I so, you there Peter, there kommt raus aus dem Spüle. Guckt der ganz irre ja, comes out out.of the sink. Looks that.one all crazed yes, 
dem ging es heute den ganzen Nachmittag schon nicht so that went it today the whole afternoon already not so besonders, ne - guckt ganz irre, und dann gucke special, no - looks all crazed, and then look ich wieder hin und dann sehe ich, wie sich ganz I again there and then see I, how itself all langsam und stetig das Waschbecken mit aeh slowly and continuously the sink with uh Wasser füllt. water fills.

'And then I say, [blowing through lips], Peter was sitting kitty corner from me, and I say, hey you, Peter, it's leaking out of the faucet. He looks real crazed, he wasn't doing particularly well all afternoon today, right - he looks real crazed, and then I look at it again and then I see, how the washbasin fills up with water slowly and continually.' (CallHome)

In the above verb-initial clause types, the utterance-initial predicates can have their full set of core semantic roles realized. In other constructions, the ones that Auer (1993) calls cases of improper or pseudo V1 (uneigentliche Verbspitzenstellung), one of the arguments is null-instantiated. Of these constructions, the most frequent type may be the imperative (4). Some other subject-drop constructions with a finite verb are found in written language, too. Among them are statements on product labels (6); representations of interior monologue (21) or of speech (22), and diary style (23). ${ }^{10}$

(21) Halbfett. Hinter dem Autorinnennamen. Einfach so, der semi-bold after the author name. simply so, the Name und ein Punkt. $\emptyset$ Kommt gut. Wirkt sicher. name and a period. $\varnothing$ comes well. Appears certain. Hat was von Definitivität.

Has something of definiteness.

'Semi-bold. Following the author name. Just like that, a name and a period. $\varnothing\{$ Comes\} across nice. Looks assured. Looks definitive.'

(22) Statt dessen schlägt er den Abschuß eines Balles instead that.of puts he the kicking one.of ball vom Kopf vor. Ist Tell, sagt er. $\varnothing$ Kommt gut, from head forward. Is Tell, says he. $\emptyset$ Comes well,

10 Haegeman (1990) provides a discussion of omissions in diary style. 


$\begin{array}{lllll}\text { sagt er. } & \text { Hammers? } & \text { fragt } & \text { Dahlmann. Nicht } \\ \text { says he. } & \text { Have.we.got.it? } & \text { asks } & \text { Dahlmann. Not } \\ \text { ganz, } & \text { sagt } & \text { Kerner. } & & \\ \text { completely, sayst } & \text { Kerner. } & & \end{array}$

'Instead he proposes kicking a ball off somebody's head. Is Tell, he says $\varnothing\{$ Comes $\}$ across nice, he says. We finished, asks Dahlmann? Not quite, says Kerner.'

(23) $\varnothing$ Bin immer noch beim Sichten, es werden immer

$\emptyset$ Am always still at.the screening, it become always weniger verschiedene Stapel.

fewer different piles.

' $\emptyset\{\mathrm{Am}\}$ still sifting, the piles are getting fewer.'

In addition to the preceding subject-drop constructions, German also allows the null-instantiation of objects and clausal complements in verb-initial constructions, typically in the spoken variety. In (24), the bare infinitive complement of wollen ('want') is omitted, while in (25) an embedded question complement of wissen ('know') is omitted. (Alternatively, an anaphoric pronoun such as das ('that') may be taken to be omitted in (24) and (25).)

(24) So viel Fußball wie in den letzten 5 Wochen hab So much soccer as in the last 5 weeks have ich noch nie verpasst. $\emptyset$ Will ich auch nie I still never missed. $m$ Want I also never wieder. Aber. 3 Wochen Berlin sinds noch. again. But. 3 weeks Berlin are.it still.

'Never missed out on as much soccer as in the last 5 weeks. I don't \{want\} $\emptyset$ ever again. But there's still 3 weeks in Berlin.' (Twitter)

(25) Was ziehst du heute an? - Oehm $\emptyset$ weiß What pull you today on? - Ahem $\emptyset$ know ich nicht!

I not!

'What are you putting on today? - Ahem, I don't $\{$ know $\}$ !' (Twitter)

Actually, if one assumes that an anaphoric dann is omitted from examples (18) and (19), then those examples could be said to exhibit topic-drop, too. 
Auer (1993: 194) also lists other types of pseudo-V1. Among these are, for instance, parenthetical reporting clauses (26), and main clauses of sentences beginning with a subordinate clause (27).

(26) Freilich, sagte Eduard, hilft das Hin- und Widerdenken, Of.course, said Eduard, helps the to- and fro.thinking, das Hin- und Widerreden $\mathrm{zu}$ nichts. the to- and fro.talking to naught. 'Of course, said Eduard, the thinking to and fro, the talking to and fro doesn't help at all.' (=Auer 1993: 194, example (vi))

(27) Ja, wie er sie auf dem Papier sah, fing Yes, as he her on the paper saw, started er bitterlich an $\mathrm{zu}$ weinen. he bitterly up to cry.

'Now, when he saw them on paper, he began to shed bitter tears.'

I will set these additional types aside here because they do not have the verb in sentence-initial position and extracting them automatically is not trivial. Generally, for my purposes I use the label V1 in a very surface-oriented way: I will speak of all of the above types of omissions where the finite verb seems to be appear in the V1-position as V1-constructions, even though the topic-drop constructions in particular are treated as involving V2 in syntactic theories that assume empty elements (Schalowski 2009).

\subsection{Frequency of verb-initial utterances}

Since the automatic tagger ${ }^{11}$ that I use is likely to make a considerable number of mistakes on the Twitter data due to, for instance, unusual punctuation as in (28) and since tweets contain elements that are not directly part of utterances, I handchecked a set of 200 tweets selected at random from the full corpus. In looking for verb-initial utterances, I also accepted cases where the first token in the post was a form of address marked by “@” (cf. [29]) or a topic marking hashtag (28). In the end, I found 16 tweets with an initial verbal form. 6 of them were yes/noquestions, the remaining 10 were cases of subject pro-drop such as (29).

11 It is a version of the TreeTagger (Schmid 1994) with a slightly adapted lexicon, kindly provided to me by my colleague Ines Rehbein. 
Table 3: Percentage of verb-initial units.

\begin{tabular}{lr}
\hline Twitter & $8 \%$ \\
CallHome & $3.5 \%$ \\
Bundestag & $2.5 \%$ \\
deWaC & $1.5 \%$ \\
HGC & $1 \%$ \\
\hline
\end{tabular}

(28)

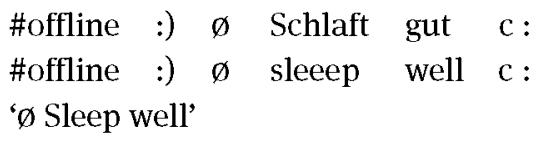

(29) @nwpxOdi ø Klingt gut. Wenns Wetter passt bin ich @nwpxOdi ø sounds good. if.the weather fits am I dabei . therewith .

‘@nwpxOdi ø \{Sounds\} good. If the weather’s fine, I’ll come along.'

The share of verb-initial sentences in my Twitter data thus is about $8 \%$. To see how this compares with the rate of verb-initial sentences in other corpora, I repeated the exercise by hand-checking samples of 200 randomly sampled sentences. ${ }^{12}$ The results are shown in Table 3. As can be seen, Twitter has the highest rate of verb-initial units by far among the five corpora.

\subsection{Construction types in a sample of verb-initial sentences}

Table 4 shows the distribution of V1-constructions random samples of size $\mathrm{N}=100$ from my five data sets. All samples were extracted by specifying a verbal form as the first token in the sentence. The first column, Type, classifies each con-

12 An important caveat about the analysis of the tweets is that my sample is somewhat biased: some tweets consist of more than one sentence but I always considered only the first sentence in the tweet. The decision to look only at the first sentence of the tweet is motivated by the fact that automatic sentence splitters perform poorly on Twitter data. So rather than also perform the sentence splits by hand, I decided to only look at the first sentence in a tweet. In tweets with more than one sentence, the first sentences may have different semantic-pragmatic characteristics than later sentences and so I am likely not getting the same rate of verb-initial sentences as I would have, had I been able to access all sentences in the Twitter data. 
Table 4: Frequencies of verb-initial constructions.

\begin{tabular}{|c|c|c|c|c|c|c|}
\hline & Type & $\mathrm{HGC}$ & deWaC & Twitter & Bundestag & CallHome \\
\hline $\begin{array}{l}\text { Conditional/concessive } \\
\text { inversion }\end{array}$ & $\mathrm{P}$ & 22 & 32 & 2 & 4 & 0 \\
\hline Exclamative & $P$ & 2 & 0 & 2 & 2 & 0 \\
\hline Apodosis stranding & $\mathrm{P}$ & 0 & 1 & 0 & 0 & 1 \\
\hline Formulas & $\mathrm{I} / \mathrm{P}$ & 0 & 1 & 0 & 0 & 12 \\
\hline Reporting inversion & $P$ & 0 & 0 & 0 & 0 & 2 \\
\hline$d a$-drop & $P$ & 0 & 0 & 0 & 0 & 4 \\
\hline Presentational inversion & $\mathrm{P}$ & 0 & 0 & 3 & 0 & 0 \\
\hline Contrast inversion & $\mathrm{P}$ & 4 & 0 & 0 & 0 & 0 \\
\hline Yes-No-questions & $P$ & 53 & 22 & 31 & 45 & 32 \\
\hline Formal imperative & $\mathrm{P}$ & 0 & 10 & 1 & 32 & 0 \\
\hline Infinitive imperative & $P$ & 0 & 0 & 1 & 0 & 0 \\
\hline Hortative/Optative & $P$ & 0 & 4 & 0 & 16 & 0 \\
\hline Informal Imperative & I & 9 & 12 & 13 & 0 & 4 \\
\hline Subject topic-drop & । & 8 & 15 & 34 & 1 & 25 \\
\hline Subject expletive drop & I & 0 & 4 & 6 & 0 & 3 \\
\hline Cataphoric subject drop & I & 2 & 0 & 2 & 0 & 0 \\
\hline Object topic-drop & । & 0 & 0 & 5 & 0 & 17 \\
\hline Total & & 100 & 100 & 100 & 100 & 100 \\
\hline
\end{tabular}

struction as either belonging to the proper (eigentliche) V1-constructions or to the improper (uneigentliche) set.

The constructions in Table 3 have all been exemplified above except for what I called formulas. This basically refers to two items, sag(e) mal ('say') and weißt $\mathrm{Du}$ ('you know'), used sentence-initially but of somewhat doubtful status as matrix-clause predicates. In the interest of surface-oriented analysis and because they seem to function in a distinct way as interactive units in the sense of Zifonun et al. (1997: 62), I counted these items as separate cases of V1 rather than include them under their related form-types, the informal imperatives and the yes/no-questions.

Unsurprisingly, the interactive units sage(e) mal ('say') and weißt du ('you know') are most distinctive for the spoken CallHome corpus, which also has the highest proportion of personal and demonstrative pronouns, response particles, and references to the here (hier) and now (jetzt), in line with its representing synchronous, though not face-to-face communication. Note that interactive units do occur in the other data sets, too. They just happen not to be represented in my particular random samples of V1-constructions. Other constructions that are distinctive for the spoken CallHome corpus include subjectand object-drop constructions, which according to Zifonun et al. (1997)'s 
typology are instances of situational ellipsis, relying on speaker-hearer synchrony. Object-drop occurs only in the CallHome and, with lesser frequency, in the Twitter samples. On the other hand, subject drop is even more common in the Twitter sample than in the CallHome sample. Altogether this suggests that Twitter data has characteristics of spoken conversation. Of course, the use of drop constructions on Twitter may also be motivated as a kind of structural ellipsis in a medium with constraints on message-length. It is also interesting to note that drop-constructions do not figure much at all in the Bundestag corpus, which is medially oral but conceptually written. With regard to omissions, the parliamentary speeches seem more 'written' than the HGC newspaper corpus.

In addition, the CallHome sample is the only one that contains instances of $d a$-drop and reporting inversion, shown in (30), which one might consider a subtype of $d a$-drop.

(30) Ich habe schon gesagt Mensch, ich habe zum Klaus gesagt, I have already said Man, I have to.the Klaus said, ich habe es ihm vorgespielt, habe gesagt, I have it to.him played, have said, sage mal hat die Rosi einen traurigen Ausdruck oder say again has the Rosi a sad expression or aufgeregt. Sagt er nee, ganz normal. Sage irritated. Says he no, totally normal. Say ich, so ungewöhnlich, keiner hat Geburtstag, I, so unusual, nobody has birthday, nix fällt an. nothing falls on. 'I said, man, I said to Klaus, I played it for him, I said, say, doesn't Rosi look sad or irritated. Says he, no, totally normal. I say, so unusual, it's nobody's birthday, there's nothing coming up.'

Yes/no-questions are most common in the HGC corpus sample, followed by the Bundestag sample, and then Twitter and CallHome. It remains to be investigated what functional roles these questions play in the various corpora. A similar question arises with respect to the various types of imperative constructions found in the corpora. They are particularly frequent in the Bundestag data, where the large subset of optatives/hortatives is notable. The conversational CallHome corpus by contrast contains very few instances of imperatives, even though these constructions are hearer-oriented and, thus, very much compatible with synchronous conversation. 
Inversions in conditional protases (cf. [16]) are (almost wholly) absent from the Twitter and CallHome samples, which is not surprising since these constructions typically go along with considerable sentence-length.

I return now once more to the drop-constructions. In the Twitter and deWaC data, 'dropped' initial constituents were not always topics: I found quite a few cases of expletives being dropped (see Section 6.1). Also, some of the V1-formulations that I found alternate with overt versions where a cataphoric pronoun would precede the verb, as in (31).

$\begin{array}{llllll}\varnothing \quad \text { Bleibt nur } \mathrm{zu} \text { hoffen, daß } & \text { angesichts der } \\ \varnothing \quad \text { Remains } & \text { only to hope, that in.the.face.of the } \\ \text { ausgeprägten } & \text { Debattierfreudigkeit } & \text { der } & \text { Abgeordneten } \\ \text { pronounced } & \text { debate-happiness } & \text { the.of representatives }\end{array}$

nicht plötzlich ein Streit über die Frage entbrennt, not suddenly a dispute over the question flares.up, warum der Schwarzwald nicht vertreten ist? why the black.forest notw represented is?

'[It] \{remains\} to be hoped that, given the extensive debate-happiness of the representatives, there won't arise a dispute about the question why the Black Forest is not represented?' (HGC)

In addition, the distribution of the different drop-constructions differs between the corpora. Subject drop is more common in the Twitter data than in the other samples, while object drop is most common in the CallHome sample. Moreover, in the case of subject drop, the samples differ not only in the relative frequency but also in the person feature of the dropped subject referents, as shown by Table 5 .

The dropped subject topics in the HGC are always 3rd person referents, while in the Twitter data they are somewhat more likely to be 1st person referents than 3rd person referents. This difference may just reflect the fact that 1st person subjects in general are much rarer in the HGC than in the Twitter data: in a sample

Table 5: Person feature of dropped subject referents.

\begin{tabular}{lrrrrr}
\hline & HGC & deWaC & Twitter & Bundestag & CallHome \\
\hline $1^{\text {st }}$ Ps. & 0 & 10 & 19 & 0 & 0 \\
$2^{\text {nd }}$ Ps. & 0 & 0 & 2 & 0 & 4 \\
$3^{\text {rd }}$ Ps. & 8 & 9 & 13 & 1 & 41 \\
Total & 8 & 19 & 34 & 1 & 45 \\
\hline
\end{tabular}


from the HGC of 200 verbal predicates, there were only 3 cases of overt first-person subjects, while in a parallel Twitter sample there were 31. In the deWaC sample, the distribution is overall similar to that found in the Twitter sample. The most surprising finding is the fact that the CallHome sample patterns most closely with the written HGC corpus: its omissions predominantly concern 3rd person referents and there were no 1st person cases at all.

Finally, I note that the cases of object-drop in the Twitter data all concern 3rd-person referents, which matches Schalowski (2009)'s finding for the instances of object-drop in a corpus of online forum posts. Similarly, according to a chi-square test, the distribution of person features among the dropped subject referents in the Twitter data in Table 5 cannot be distinguished from the distribution that Schalowski (2009) found for the dropped subjects in his social media data set.

To sum up: the types of V1-constructions are distributed very differently across the corpora. Some types such as conditional inversion seem to be largely restricted to the newspaper data, while others such as topic-drop occur mostly in the spoken corpus. However, no overall clear picture emerges based on my 5 data sets with respect to which data sets are most similar to each other. What does seem clear is that the Bundestag corpus is the corpus that is most different from all the others with respect to the patterning of V1-constructions. And Twitter is the corpus that uses the largest share of improper V1-constructions that are accompanied by argument-drop. Taken together with the fact that Twitter also has the highest V1-rate, as shown above in section 5.1., it seems that the constraints of the medium with respect to message-length are reflected in a higher use of improper V1-constructions that allow greater information density through omission of recoverable material.

I conclude the section with a quantitative caveat. The counts derived from the five samples may suggest that some constructions figure in only one or two of the two corpora. For instance, cases of contrast inversion were found only in the HGC sample; conditional inversion is mostly a feature of edited written language; instances of presentational inversion were only found in the Twitter sample. While one can be fairly confident about the distribution of conditional inversion where I found relatively large numbers in relation to the small sample size, one cannot be so sure about the other two constructions that have much lower frequencies: Would the differences between corpora showing up in my samples stably reappear in larger samples? Minimally one has to keep in mind that my corpora do not represent the totality of the respective text or media types involved. To see this, one just has to recall that, for instance, the HGC does contain instances of presentational inversion - after all, example (15) is taken 
from that corpus - or that Auer (1993) and Günthner (2000: 15-19) have shown that presentational V1-constructs play important roles in spoken language (such as creating cohesion with prior context or providing for more lively/dramatic narration).

\section{Argument drop in active-form declarative clauses}

In this section, I specifically consider sentences in which an argument is omitted by construction in a finite active-form declarative clause. The general question that I ask is whether all such omissions result from a single unitary topic drop construction or whether there are different types of constructions at play. I first consider cases in which the dropped elements are expletives, that is, syntactic arguments only, but without a semantic role. Afterwards, I examine what constraints exist on such omissions and what kind of grammatical analysis should follow from them.

\subsection{Expletive-drop in the Twitter data}

Expletives are defined to be non-referential nominals that serve to fill certain structural requirements, in particular one for a clausal subject to be present. Given their non-referring status, expletives should not be able to be targeted by topic drop, and this claim is in fact made by Fries (1988: 34). Fries is, however, aware that some omissions of expletives can be found but explains them away as cases that may be acceptable to speakers (though still not grammatical) because topic-drop is a phenomenon at the margins of German grammar where judgments are expected to be less crisp.

I will not adopt such a view and instead treat expletive drop as an ordinary construction of (conceptually) spoken German, especially since in the Twitter data one does encounter omitted expletives quite frequently. Table 6 shows the subject realizations of five verbs denoting precipitation events in the Twitter data set. While the number of instances is small, one can see that expletive drop is attested with all of the verbs, though it may be more common with one of them (regnen) than with the others. ${ }^{13}$

13 Note that the results for schneien ('snow') are from a newer Twitter data set. The corpus used throughout the paper was collected during the summer of 2012 and therefore contains no mentions of snow and snowing. 
Table 6: Realization of expletive with weather predicates.

\begin{tabular}{lccccc}
\hline Form & regnen & pissen & nieseln & schiffen & schneien \\
\hline & 'rain' & 'rain hard' & 'drizzle' & 'rain hard' & 'snow' \\
zero & 11 & 1 & 1 & 10 & 1 \\
das & 3 & 2 & 1 & 2 & 1 \\
es/'s & 23 & 61 & 41 & 33 & 96 \\
other & 0 & 1 & 0 & 0 & 0 \\
Total & 37 & 64 & 42 & 45 & 98 \\
\hline
\end{tabular}

I also looked for the verb regnen in my other corpora, inspecting 200 random instances (fewer, if fewer were available in the corpus). Basically, I found almost no zero-realizations in the samples from the Bundestag (0/5), CallHome $(0 / 11)$, deWaC $(1 / 200)$, and the HGC $(0 / 200)$. However, since there are very few instances of the predicates involved in the CallHome and the Bundestag data, I cannot come to any confident conclusions about expletive-drop with regnen there.

Returning now to the analysis, one may ask whether expletive-drop behaves like topic drop or not. One important aspect in which it does behave like topic drop is the fact that it seems acceptable only if there is nothing occupying the prefield. While in (32) the canonical versions (a) and (c) are acceptable, dropping the expletive is only acceptable in (b) but not in (d).

(32) Today it's \{raining cats and dogs.

$\begin{array}{clllll}\text { a) Es } & \text { regnet } & \text { in } & \text { Strömen } & \text { heute. } \\ \text { It } & \text { rains } & \text { in } & \text { streams } & & \text { today. } \\ \text { b) } \varnothing & \text { Regnet } & \text { in } & \text { Strömen } & & \text { heute. } \\ \varnothing & \text { Rains } & \text { in } & \text { streams } & & \text { today. } \\ \text { c) Heute } & \text { regnet } & \text { es } & \text { in } & \text { Strömen. } & \\ \text { Today } & \text { rains } & \text { it } & \text { in } & \text { streams. } & \\ \text { d) \# } & \text { Heute } & \text { regnet } & \emptyset & \text { in } & \text { Strömen. } \\ \# & \text { Today } & \text { rains } & \emptyset & \text { in } & \text { streams. }\end{array}$

The unacceptability of (d) is unexpected if expletive drop is owed to a different, independent licensing mechanism from topic drop: if expletive drop has nothing to do with discourse status, why should sentence position matter?

It is also my impression that expletive drop is associated more with spoken language than with written language, as is the case for topic drop. In the written language, one does not tend to find cases of missing expletives, as noted above. 
One example contained in the deWaC, though not part of the sample examined above, occurs in a literary quote from Döblin's Berlin Alexanderplatz, which, suggestively, involves interior monologue:

(33) Raus auf die Straße! Luft! $\emptyset$ Regnet noch immer. Out onto the street! Air! $\emptyset$ Rains still always. Was ist nur los? Ich muß mir ne andere nehmen. What is only up? I must me an other take. Erst mal ausschlafen. Franz, wat is den mit dir los? First once out.sleep Franz, what is then with you up? 'Out into the street! Air! ø Still \{raining\}. Just what is going on here? I have to find another one. First a good night's rest. Franz, what is the matter with you?' (HGC)

However, without a larger database I cannot verify how frequent subject-less expletives are with weather predicates in conversational language.

\subsection{Constraints on topic drop}

In section 5.2 we saw that the HGC, Twitter and CallHome data contain instances of topic drop for subject and object arguments. Of the two kinds of arguments, subject drop was much more common for the HGC and Twitter data, but less pronouncedly so in the conversational CallHome corpus.

Although topic drop is assumed to be motivated by high accessibility - in Schalowski (2009)'s words, topic drop targets familiarity topics - it seems unable to apply to arguments other than subjects and objects whatever their accessibility. Notably, indirect objects seem not to be droppable; a failed attempt of omitting a third person indirect object is given in (34). ${ }^{14}$

(34) \# $\varnothing$ Helfe ich morgen bei den Hausaufgaben. \# $\varnothing$ help I tomorrow with the homework 'I'll help ø [them] tomorrow with their homework.'

Twitter data that I inspected for verbs such as helfen ('help'), schenken ('give as gift'), spenden ('donate') did not yield any instances that were recognizable as

14 It is possible to drop the indirect-object in some cases: Hilft beim Abnehmen ('Promotes weight loss')[lit. Helps with losing weight]. However, this seems to be limited to generic statements, especially ones about the efficacy of means and instruments. 
topic drop. The finding that indirect objects cannot be dropped is very surprising given that indirect object referents are generally coded in a way that suggests very high accessibility.

Similarly, it has been held that prepositional phrase arguments cannot usually be dropped. While I did not find an instance in the Twitter data, I was able to find an example in a web forum. In (http://www.gtrp.de/archive/index.php/ t-1152.html), the Content argument of the verb erinnern ('remember') in user Eki's reply is omitted with the verb in utterance initial position and the subject and reflexive object realized, which suggests that the construction used is topic drop.

(35) Chakra ${ }^{15}$

So, habe jetzt meinen Tommi Mäkkinen IA1

So, have now my Tommi Mäkkinen IA1

Endurance von 9 Stunden mit "Genau mein Ding" überboten Endurance of 9 hours with "Just my thing" exceeded -you remember, Eki-

-you remember, Eki-

Die Kombo macht 'nen Riesenspaß, obwohl ich mich That combination makes a lot-of-fun, though I myself irgendwo immer verfranse: rolleyes:

somewhere always entangle: rolleyes:

Ja, Flinx, kann mir gut vorstellen, daß Du 1:31 schaffen Right, Flinx can myself well imagine, that you 1:31 make kannst, bzw. als virtuelle lap-time schon hast :) Bin can, resp. As virtual lap-time already have :) Am jedenfalls gespannt. in.any.case on.tenterhook.

'So, I've now outdone my Tommi Mäkkinen IA1 Endurance record of 9 hours with 'Just my type of thing' -you remember, Eki. That combination is a lot of fun, though I always get tangled up somewhere. Right, Flinx, I can well imagine that you can make 1:31 or have already done so as a virtual lap-time ;) In any event, I'm on tenterhooks.'

\section{Eki}

$\emptyset$ Erinner ich mich gut; jaja, der Tommy.

$\emptyset$ Remember I myself well; yes-yes the Tommy.

'I remember\} ø well; yes, yes, Tommy ....' 
While the above example seems like a very clear case, there are additional instances that could arguably be seen to involve topic drop of a prepositional argument. In (36), the verb (darauf)kommen in the relevant sense ('think of/hit on') requires an auf-PP encoding a Content semantic role. However, when the Content semantic role is anaphorically accessible, the anaphoric form darauf, which fuses the preposition with a demonstrative pronoun, is standardly used, as in (37). An anaphoric element $d a$ can also be fronted in a kind of reduplicative construction (cf. [38]). The sentence in (36) could thus be seen as involving the dropping of the initial $\mathrm{da}$ found in (38).

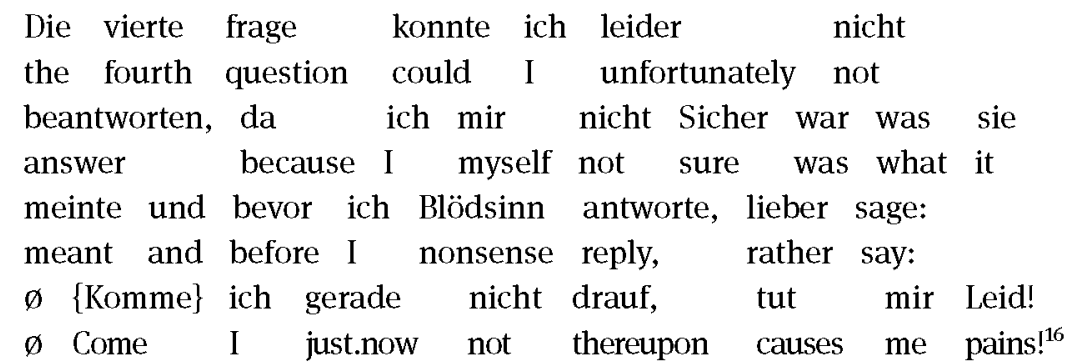
'Unfortunately, I couldn't answer the fourth question because I wasn't sure what she meant and rather than reply with some nonsense, I prefer to say "I can't \{think\} ø [of it] right now, sorry!"

Ich komme gerade nicht darauf/drauf.
I come just.now not thereupon.
'Just now I can't think of it.'

(38) Da komme ich gerade nicht drauf/darauf. There come I just.now not thereupon. 'Just now I can't think of it.'

Now, one might object that in (36) above, the anaphoric element is fully instantiated in the fused form and if anything is omitted sentence-initially, it might just be an adjunct. This objection would however not apply to cases like (39) below, where the verb halten ('to hold') occurs in a sense ' $\mathrm{X}$ holds $\mathrm{Y}$ in $\mathrm{Z}$ regard' that requires a von-PP encoding the evaluated entity. In standard written German, the sentence would have to be formulated as in (40), with an element fusing the preposition and the anaphoric element. In example (39), the anaphoric element is

16 (http://www.bundeswehrforum.de/forum/index.php?topic=23969.5;wap2) 
completely missing but has to be understood. Moreover, the initial position of the verb suggests again that a topic drop construction is being used. If that is correct, then it is an instance of topic drop that does not involve a subject or object. (For Fries (1988), the above examples are a special case of the phenomenon that he basically calls Pronoun Zap following Huang (1984). He refers to them as anaphor deletions.)

(39) @hertizworld Genau. Ein Spieler der abgestiegen ist, wird @hertizworld Exactly. a player who descended is, will uns weit nach vorne bringen. Ne, $\emptyset$ halte ich us far to forward bring. No, ø hold I nichts von. Weder so noch so. nothing of. Neither so nor so. 'Exactly. A player who was relegated will take us forward. Nah, I don't \{believe\} in ø [that]. Neither one way nor the other.' (Twitter)

(40) Nein, Davon halte ich nichts.

No, thereof hold I nothing.

'No, I don't consider it useful at all.'

Finally, I return to cases of protasis-drop, as seen in examples (18) and (19) above. Example (18) is repeated here for convenience:

$\emptyset$ Gehe ich halt ohne Hose los!
$\emptyset$ Go I just without pants off!
‘ $\emptyset$ So then] I'll just go off without pants' (Twitter)

A plausible analysis is that sentence (41) drops an anaphoric dann, marking the contextually given protasis. While temporal dann is ordinarily an adjunct, the dann in such a conditional context has to be seen as one of the two situation-denoting arguments of the conditional construction. On that analysis, sentence (41) also is a case of argument topic-drop, but of an argument with adverbial form. Neither Fries (1988) nor Schalowski (2009) discuss these cases in the context of topic drop. ${ }^{17}$

17 The description of the kind of usage found in (41) is probably still incomplete. For instance, it seems that the conditional consequent typically is used in an exclamative context, including a discourse marker such as halt. 


\subsection{Non-inflectional constructions}

Twitter data, like other computer-mediated communication, also exhibits non-inflectional constructions, a stylistic device that is commonly found in comics (Schlobinski 2001). The prototypical instance of this kind of construction consists of a bare verb stem as in example (42).

(42) Dann halt nicht schlafen. *aufräum*

Then just not sleep. *tidy.up ${ }^{\star}$

'No sleeping then. *Tidying up*'

(43) *Bagelmampf* sooo lecker :)

*Bagel munch* sooo good :)

‘`Munching bagels^ soooo good :-)'

In example (43), the uninflected verbal form is preceded by a verbal argument. ${ }^{18}$ On Twitter, instances of this construction are usually marked by inclusion in a pair of asterisks. The verbal forms that occur in such contexts are commonly called inflectives following Teuber (1998), who discusses the place of these forms within the morphological paradigm of German. But as is shown by example (43), uninflected verb forms can also occur together with arguments or modifiers. ${ }^{19}$ Following Bücking and Rau (2013), I will refer to the actual occurrences of uninflected verb forms together with any arguments and modifiers as non-inflectional constructs (NICs), which avoids confusion with the use of the term for the morphological property of being subject to inflection.

Based on my corpus work, it seems that the functional purposes of non-inflectional constructs, or a very similar set of purposes, can also be subserved by forms that are in fact inflected, as shown by (44), or that are not verbally headed at all, as shown by (45).

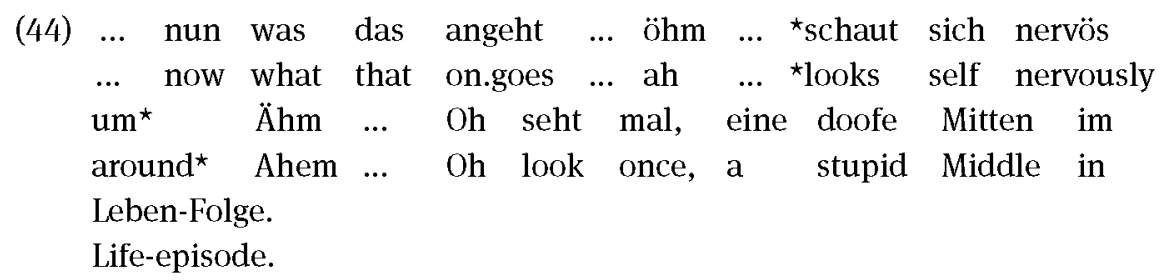

18 I will simply call the relevant verb forms uninflected rather than commit to a characterization as verb stems or zero-inflected verb forms.

19 There is a question to what extent incorporation of such arguments or modifiers occurs in actual uses of non-inflectional constructs, correlated to some degree with spelling as a single word. I will not address this issue here (but see Schlobinski 2001). 
'well, with regard to that ... ahem *looks around nervously" ahem ... Oh look, a stupid episode of "In the Midst of Life".'

(45)

$\begin{array}{lllllll}@ \text { @schattenbran } & \text { Du } & \text { weist } & \text { warum } & \text { :D } & { }^{\star} \text { dreckiges } & \text { lachen* } \\ \text { @schattenbran } & \text { You } & \text { know } & \text { why } & \text { :D } & \text { *dirty } & \text { laughter }\end{array}$

'You know why :D * dirty laughter"'

I will reserve the term non-inflectional construct for cases headed by uninflected verbs. I will call cases such as (44) and (45) pseudo-non-inflectional constructs (PNICs).

What interests me about the verbal cases is their argument structure since normally non-inflectional constructs lack at least one of their semantic roles, the one that would be realized as subject in finite active-form sentences. To study the argument structures of non-inflectional constructs, I drew a random sample of 500 tweets. Each candidate tweet to inspect was initially identified based on the criterion that it contained a token starting with an asterisk. I checked all the candidate tweets by hand and excluded pseudo-non-inflectional constructs such as (44) and (45) above and cases where the asterisks are used for other purposes such as emphasis, as in (46), as well cases where it was not clear what the function of the asterisk was. For instance, in (47), it seems the writer might mark the playful use of a foreign word-phrase (FrenchEnglish "le me").

(46)@BassLove_ ja wenigstens durft ich kaya *ich hab @BassLove_ yes at.least allowed.was I kaya I have geheult als die karten da warn* cried when the tickets there were* 'at least I was allowed to kaya ${ }^{\star}$ i cried when the tickets got here ${ }^{\star}$ '

(47) ${ }^{\star}$ Le me geht jetzt mal zum Briefkasten! ${ }^{\star}$ Le me goes now once to.the letterbox!

'Le me [the me] is going to the post box now.'

Regarding the function of non-inflectional constructs, Teuber suggested that they mainly serve to express a subjective response or appraisal. This applies to many examples but as (42) and (43) show, it is not always the case. Let us compare (43) above with the alternative formulation in (48).

(48) (Ich) mampfe eine Bagel sooo lecker :)

(I) munch a bagel. sooo good :)

' $\emptyset$ Munching a bagel. soooo good :-)' 
It seems that by using the NIC formulation, the speaker asks the hearer to treat the information communicated by the non-inflectional construct as if they had observed it, rather than been told about it. Similarly, Bücking and Rau (2013: 85) characterize non-inflectional constructs as having a performative function: "they do not merely describe concomitant actions but present them as being in fact performed and thus despite factual distance accessible to immediate perception". If these ideas are on the right track, use of NICs on Twitter serves to re-create a sense of face-to-face or multi-modal communication that distant communication by a broadcast medium like Twitter does not offer. The question is whether one should treat cases such as (42) and (43) as different from ones like (49), where the NIC references an emotional state or appraisal.

(49)@R3b3ccaCran3 ${ }^{\star}$ dich hass ${ }^{\star}$ Wir sind extra um 6 $@$ QR3b3ccaCran3 ${ }^{\star}$ you hate ${ }^{\star}$ We are extra at 6 aufgestanden, damit wir sie schauen können $<3<3<3$ morgen risen, so.that we them watch can $<3<3<3$ tomorrow auch wieder

also again

'^hating you' ${ }^{\star}$ We specially got up at 6 so we could watch them $<3<3<3$ same again tomorrow.'

(49) seems to be a case where the NIC very clearly conveys an internal state. However, one could still think of it as replacing missing multi-modal information: people in general are very good at recognizing emotion in others based, for instance, on facial expression and tone of voice. Bücking and Rau (2013) also assume a single analysis for all non-inflectional constructs.

I now turn to the analysis of the form and argument structure of the non-inflectional constructs in my sample. The 500 candidate tweets inspected contained 206 NICs. 9 of these cases had reduplicated uninflected verb forms of the type freu-freu ('happy-happy'), quietsch-quietsch ('shriekshriek'), etc. All the NICs with reduplication were based on intransitive verbs. With the exception of example (50), all NICs were oriented towards a first-person subject. ${ }^{20}$

20 Of course, example (50) also involves the author of the tweet as an experiencer, though that role is not realized as a subject with the idiom das Wasser im Mund(e) zusammenlaufen 'salivate [lit. the water is collecting in one's mouth]'. 
Table 7: Distribution of patterns with frequency greater than 1.

\begin{tabular}{lr}
\hline $\mathbf{V}$ & $\mathbf{3 4}$ \\
\hline ObjNP-V & 32 \\
ObjNP-PartV & 28 \\
PP-V & 16 \\
Adv-V & 7 \\
ObjNP-PP-V & 6 \\
Adv-PartV & 6 \\
PartV & 5 \\
PP-PartV & 4 \\
ObjNP-PP-PartV & 4 \\
IndObjNP-ObjNP-PartV & 4 \\
Adj-V & 4 \\
PP-PP-V & 3 \\
ObjNP-V-Clause & 2 \\
NP-PartV & 2 \\
IndObjNP-ObjNP-PP-V & 2 \\
Adv-PP-V & 2 \\
Adv-ObjNP-V & 2 \\
Total & 163 \\
\hline
\end{tabular}

(50) Geil! *Wasser im Mund zusammenlauf* RT Sweet! *Water in.the mouth collect ${ }^{\star}$ RT (a) ChrissyRamone: (ChrissyRamone:

La Fischtheke au Wissembourg.

La Fischtheke au Wissembourg. ${ }^{21}$ 'Sweet! *Salivating *'

Table 7 shows the distribution of patterns for the prototypical case, noninflectional constructs based on a simple uninflected verbal form. It lists only the patterns with more than 1 instance. In addition to those patterns, there are 32 other unique patterns represented in the sample. In table 7, I distinguish particle verbs from simple verbs by the label PartV in order to draw attention to their high frequency among the NICs.

As shown by Table 7, most of the instances do not match Teuber (1998: 21)'s characterization as one-word sentences. While one-word instances consisting of just a predicate as in example (42) are frequent, instances where an uninflecd

21 http://t.co/89qXIT3Q 
verb form occurs together with one or more non-subject complements or adjuncts are much more common. Schlobinski's (2001) data show many complex NICs, too. Further, many examples in my sample as well as many of the ones shown in Schlobinski (2001)'s work, contradict Teuber's (1998) analysis that NICs have a syntactically empty valence. An incorporation analysis would not work for cases where specifically referring NPs appear as arguments of uninflected verbs within non-inflectional constructs, as in (51).

(51) @HoneyballCookie Ich war heute mit Papa lecker essen. @HoneyballCookie I was today with dad good eat. $\wedge \wedge$ *dir auch etwas rüberschieb* $\wedge \wedge{ }^{\star}$ you.to also something over.slide* 'Today I had a good meal out with dad. * sliding some over to you, too *'

In the majority of cases, the verbal form is placed at the end of the non-inflectional construct, which Schlobinski (2001: 206) attributes to the general fact that final position is the norm for non-finite forms in German. In my sample, the exceptions consist of cases where there is a clausal complement that is arguably shifted rightward because of its heaviness (cf. [52]).

$\begin{array}{llll}\text { @fhainalex Amt? Oha! }{ }^{\star} \text { Daumen } & \text { drück, } \\ \text { @fhainalex } & \text { Agency? Whoa! }{ }^{\star} \text { Thumb press, } \\ \text { daß alles } & \text { einigermaßen gut läuft } & \\ \text { that all } & \text { passably } & \text { well runs } & \end{array}$

'Agency? Whoa! *Keeping fingers crossed that everything works out tolerably ${ }^{\star}$,

I turn now to the verbs that occur as the heads of the non-inflectional constructs. Within my 206 instances of NICs, a large variety of uninflected forms is represented. Only 6 verbs occur more than 5 times, namely:

(53) winken ('wave') (6), drücken ('cuddle') (7), reichen ('pass'), (7), freuen ('be happy') (8), rüberschieben ('slide over') (10), lachen ('laugh') (11)

To provide some further abstraction over individual words, I labeled the verbs heading the non-inflectional constructs in my sample with their appropriate FrameNet-frame. Table 8 shows the frames that were evoked by the heads of NICs more than once. In addition, there are 54 other frames that occurred only once.

Compare Tables 7 and 8 with the following list, which contains the most frequent single-word NICs in all of the Twitter sample: 
Table 8: Frames with frequency greater than 1 evoked in non-inflectivonal constructs.

\begin{tabular}{|c|c|c|c|c|c|}
\hline Make_noise & 20 & Cause_impact & 5 & Experiener_focus & 3 \\
\hline Cause_motion & 18 & Cause_to_move & 5 & Being_attached & 2 \\
\hline Body_movement & 14 & Hold_thumbs & 5 & Cause_bodily_experience & 2 \\
\hline Perception_active & 14 & Placing & 5 & Departing & 2 \\
\hline Emotion_directed & 11 & Cause_to_move_in_place & 4 & Manipulation & 2 \\
\hline Giving & 10 & Communication_manner & 4 & Removing & 2 \\
\hline Self_motion & 7 & Facial_expression & 4 & Taking & 2 \\
\hline Hug $^{\star}$ & 6 & Intentionally_act & 4 & Waiting & 2 \\
\hline Becoming & 5 & Breathing & 3 & & \\
\hline
\end{tabular}

(54) $g$ ('grin'), hust ('cough'), lach ('laugh'), freu ('be happy'), seufz ('sigh'), gg ('grin a lot'), lol ('laugh(ing) out loud'), gähn ('yawn'), grins ('grin'), sing ('sing'), kicher ('giggle'), wink ('wave')

It seems that when one considers all kinds of non-inflectional constructs, including the ones that consist of more material than just a simple uninflected verb form, the semantics of the occurring verbs appears more varied. Of course, the usual suspects, verbs such as grinsen ('grin') and lachen ('laugh'), are well represented among the frequent cases when looking at NICs of any length, but it is apparent that many other kinds of situations, especially ones involving motion (e.g. Self_motion, Cause_to_move, Cause_motion, Cause_to_move_in_place, Giving), are also common (cf. [51]-[52]).

I now consider the realization of arguments within non-inflectional constructs. First, it is the case that in all cases in the sample, the subject argument that is filled by the author referent is unexpressed. As noted by Schlobinski (2001: 208), the speaker role is pre-set as a "default" subject. More interesting is the question to what extent objects and indirect objects are realized or omitted. As pointed out by Schlobinski (2001: 210), within the right scenario, the addressee can also be omitted, as in (55). ${ }^{22}$

(55) @MiyaSekai @SenjoVal woa ich hoff ihr schafft das $<$; $0<$ @MiyaSekai @SenjoVal whoa I hope you manage that $<$; $\mathrm{O}<$ *anfeuer!*

${ }^{\star}$ cheering on!*

'Whoa I hope you manage it - *cheering ${ }^{\star}$ '

22 of course, reflexive objects co-referring with the authors, as in the frequent instances of freu ('be happy') is also possible. 
It is notable that the non-realization of an argument role filled by the addressee is not only possible when the referent would appear as a direct object but also with certain indirect objects that normally resist omission in simple assertions in episodic contexts. An example of this is shown in (56).

(56) @tobi_SE ruhig bluut ... ${ }^{\star}$ massage geb* @tobi_SE calm blood ... ${ }^{\star}$ massage give* 'calm down ... * giving a massage*'

It is an interesting idiosyncratic fact about argument omission within noninflectional constructs that the high salience of the addressee seems sufficient to license omission where this same omission is not licensed by the lexical items or by general language constructions.

Although they are not proper non-inflectional constructs, I want to briefly consider the cases where inflected verb forms are used by Twitter authors within the asterisk-markup. One thing to notice is that while the word order is sometimes verb-final as in the case of non-inflectional constructs proper (cf. [57]), the inflected verb is in initial position in other cases such as (58), where there doesn't seem to be a clear need for post-verbal placement of the modifier based on its weight.

(57) @LederundSpitze Wer darf die neuen Worte denn alles @LederundSpitze Who may the new words then all lessen? *unsicher schaut* read? *uncertainly looks*

'So who all is allowed to read the new words? * looks uncertainly *'

(58) ${ }^{\star}$ pfeift ganz laut*

${ }^{\star}$ whistle all loudly*

'whistles very loudly'

In terms of their function, the pseudo-NICs in my data still talk about the tweet-author. They are merely presenting information about the author as if there was an external viewer present (hence the third-person person feature). However, while the third person is the dominant option, it is not the only one within pseudo-NICs. One also finds some instances of first-person pseudo-NICs, as indicated by the verbal morphology. 
(59) @Ashqtara Ich habe was für dich, ich weiß nicht @Ashqtara I have what for you, I know not ob du das schon gesehen hast. *lieber schnell flüchte* if you that already seen have. *rather quickly flee* 'I've got something for you, I don't know if you've seen it yet. *better run away quickly*’

Coming to firm conclusions about how pseudo-NICs behave is difficult since I had only 32 instances within my 500-tweet sample. In future work, I would like to test on a larger set of pseudo-NICs whether in terms of variety, complexity, and function, they are different from non-inflectional constructs proper or not. ${ }^{23}$

\subsection{Analysis: a family of argument-drop constructions}

What should one conclude about the grammar of argument drop based on the findings in Sections 6.1 and 6.2? First, I would argue that expletive drop is its own phenomenon: though it seems a lot like real subject topic drop on the surface, it cannot have the same functional/pragmatic motivation that needs to be part of the constructional analysis.

The second major question then is what one should do about the treatment of regular arguments. Before I make a proposal let us consider a bit more data. In (60), there is an uninstantiated first person referent in the subject function. If it were to be expressed explicitly, it would be realized as a personal pronoun. In (61) and (62), third person referents in the object role are uninstantiated. If they were to be explicitly realized in the fronted topic position, they would have the form of a demonstrative rather than a personal pronoun: the personal pronoun seems completely ungrammatical in (62) and the only acceptable reading for (61) with a personal pronoun would involve contrast, which, however, is not relevant in the context of the actual Twitter thread.

(60) (Ich) Bin jetzt weg.

(I) Am now off.

'I $\{\mathrm{am}\}$ off now.' (Twitter)

23 One might suspect that maybe pseudo-non-inflectional constructs are produced by authors who have not yet mastered the grammar of proper NICs, or produced automatically by a software auto-correct feature. While that cannot be ruled out for individual instances, it seems there are too many of them for them all to be just occasional errors. 
(61) Fady Malouf. (Den/?Ihn) Mag ich nicht.

Fady Malouf. That.one/?hime like I not.

'Fady Malouf. [that one/him] I don't \{like\}.' (Twitter)

(62) @KellyKoksNuss öhm (Das/^Es) weiß ich jetzt noch nicht $\stackrel{8}{\circ}$ $@$ KellyKoksNuss ahem (that(it) know I now still not 'ahem [that/it] I don't know yet' (Twitter)

Thus, it seems that the activation status requirements for subjects and objects are different. And actually, the activation status requirements for objects seem to be more like those of the omissible prepositional arguments in (36) and (39), whose overt counterparts also involve demonstrative forms with $d a$. Not only that, but both types of omission also share the constraint on the person feature: fused forms consisting of $d a$ and a preposition can only be anaphoric to third person referents, and third person referents are also the only omissible referents in object drop.

Overall, it seems that one should favor an analysis that posits at least three different argument-drop constructions: one for expletive subjects; one for referring subjects; and one for referring objects and prepositional objects. While my discussion still does not explain the non-droppability of indirect objects, the constructional analysis could handle the facts right by paying attention to grammatical functions.

Finally, I note that topic drop may also be facilitated by structure-parallelism contexts, as discussed by Fries (1988). While in (63) the omitted element in the answer would have the same form (and semantic role), there is a change in form and role between B's question in (64) and A's two possible answers. $^{24}$

(63) In Köln ist viel Streß, und wie ist es in Tübingen? In Cologne is much stress, and how is it in Tübingen? 'It's a lot of stress in Cologne, what's it like in Tübingen?'

$\mathrm{A}: \emptyset$ Ist alles ziemlich lahm

$A: \emptyset$ is all quite lame

'It's all pretty lame [there].' (= Fries' example [110])

24 If one wanted to make the antecedent explicit, it would have the form da in both cases. However, that use of $d a$ would be as a real locative adverbial in contrast to its purely anaphoric uses seen above. 
(64) A: Also Berlin mag ich.

A: So Berlin like I.

'So I like Berlin.'

B: Und Köln?

B: And Cologne?

'And what about Cologne?'

A1: ??ø Wohn/leb' ich.

A1: ?? $\varnothing \quad$ Reside/live I.

'I live [there].'

A2: ?? Ø Spielt sich doch nichts ab.

A2: ?? M Plays itself though nothing off.

'There is nothing going on [there].' (= Fries example [109])

The in-PP in (63) is neither a subject nor an object and it is not a regular prepositional complement. Still, the discourse context sets it up as a topic, which can be dropped in a sentence where the omitted constituent would play the same semantic and syntactic role. Crucially, structure parallelism is not generally necessary for topic drop, where, for instance, an aboutness-question can precede topic drop as in (65). This contrasts with example (64) where an aboutness-question regarding Cologne does not allow for the subsequent omission of a locative anaphor.

(65) Gisbert mag dich, und was ist mit dem Sascha? 'Gisbert likes you, and what about Sascha?'

\begin{tabular}{|c|c|}
\hline A: ø Mag & er \\
\hline $\begin{array}{l}\text { A: } \emptyset \text { likes } \\
\text { ‘ L Likes him, too.’ }\end{array}$ & he \\
\hline
\end{tabular}

Further investigation is needed to ascertain to what extent structural parallelism goes along with various kinds of topic drop for which it is not strictly necessary. Finally, non-inflectional constructs need to be handled by another independent construction. The word order found with the vast majority of verbal NICs is verb-final, which prevents us from treating them as a subtype of subject topic-drop. Moreover, they have a strict focus on the here and now and do not allow past tense or perfect forms reporting on past events or states, which subject-drop does. Finally, non-inflectional constructs can license omissions of arguments, especially indirect objects, which are not omissible through topic-drop. 


\section{Discussion and conclusion}

In Section 4, I used corpus data to check the plausibility of the generalization proposed by Ruppenhofer (2004) that an omitted semantic role receives the same (anaphoric or existential) interpretation across lexically licensed omissions by the members of a particular lexical class. For the lexical classes that I considered here, the generalization was indeed found to hold.

In my second study, presented in Section 5, I was interested in constructional argument omissions, in particular various forms of argument drop. Comparing data from social media and from spoken and written corpora with respect to verb-initial constructions, we saw that they differed in the frequency with which the various constructional types occurred. Focusing on argument-drop cases in particular, we saw that generally subject topic-drop was more common than object-topic drop. Object drop was most frequent in the conversational CallHome data. In the Twitter data I also found object topic-drop to be less common than subject topic-drop, in line with findings by Schalowski (2009) for another social media set. In addition, we also encountered a less expected result, namely that expletives are dropped quite frequently and that expletive drop seems, in some respects, like topic-drop even though it arguably is not a subtype of the latter.

I also looked at non-inflectional constructions (NICs), determining that they have special properties different yet again from regular subject-drop. In the case of NICs, I did not systematically look for instances in my written corpus, the HGC. Queries for highly frequent verbal uninflected forms as found on Twitter e.g. freu ('be happy') and guck ('look') yielded no results, however.

Taking a broader perspective, the findings on the data considered here fit the analysis of Ruppenhofer and Michaelis (2010) for their data, namely that argument omission can be described in terms of "constraints on argument structure, as the relevant conventions target specific semantic and grammatical roles of verbs" (p. 160). Against this background, it is not surprising to observe that, although there are family resemblances among omission-licensing constructions, these constructions also exhibit idiosyncratic differences and limitations that simply call for individual, separate treatment.

Besides the need for specific grammatical treatment, the data also illustrates that not all omission constructions are motivated the same way. While topic drop may primarily be driven by high accessibility, measurable through frequent mention and short distance to a preceding co-referring mention, other constructions may be motivated by other notions of prominence. As discussed by Ruppenhofer and Michaelis (2010), in sentences from English match reports such as (66), the object of play (typically a ball) may go unexpressed simply because it is a globally prominent referent throughout the text via the overall scenario of the game. 
(66) He hammered ø wide of Gary Walsh's exposed net.

If this analysis is on the right track, then even the superficially similar cases of subject and object drop involve different degrees of accessibility and are not motivated in exactly the same way. In the case of non-inflected constructs, it is even clearer that they serve a special communicative function and have corresponding morpho-syntactic constraints.

Finally, let us consider the question what this study has to say about the relation between conceptually spoken language and argument omission affordances. As we saw, the conversational CallHome corpus clearly has a high incidence of improper V1-constructions licensing argument omission (cf. Table 4). The Twitter data actually shows an even higher incidence. As discussed in section 5.2, on Twitter the space constraints of the medium may provide additional motivation towards reduction, beyond what applies to spoken language. ${ }^{25}$ All other corpora examined, which are more conceptually literal than the CallHome and Twitter, make much less use of anaphoric omissions enabled by improper V1-constructions. This might suggest that constructional omissions with anaphoric interpretation belong to the language of closeness (Sprache der Nähe) that is at the heart of conceptually oral language.

However, I think this point requires further study. First, one would need to accumulate more evidence that Twitter exhibits other features of oral language. And second, one needs to relate the observations here to the findings of Schwitalla (1988), who reports no significant differences in omission rates between spoken and written language. It is not quite clear, though, to what extent Schwitalla (1988)'s results are relevant. While I looked only at omissions constructionally licensed by improper V1-constructions, he may have included all types of omissions, including lexically licensed ones, in his analysis. In any event, studying the frequency of lexically licensed omissions is in itself relevant for forming a conclusion about whether argument omissions can serve as an index of the language of closeness. The idea makes sense to me in terms of the communicative conditions and implementation strategies that Koch and Oesterreicher's (1985) discuss. In terms of the code, the exploitation of omissions raises the information density of the text, making it more compact. In terms of the communicative requirements for omissions to succeed, some or all of the factors such as face-to-face interaction, involvement, dialog, familiarity, and situational interlocking that Koch and Oesterreicher (1985) mention do seem relevant to each of the anaphoric omission

25 In future work, I plan on studying a corpus of electronic text messages (sms) in order to verify if constraints on message-length have a similar effect on the frequency of anaphoric omissions there, too. 
constructions. I therefore consider it a worthwhile topic for further research to see to what extent the frequency of anaphoric omission constructions correlates with conceptual orality.

\section{References}

Ariel, Mira. 1988. Referring and accessibility. Journal of Linguistics 24. 65-87.

Auer, Peter. 1993. Zur Verbspitzenstellung im gesprochenen Deutsch. Deutsche Sprache 3. 193-222.

Baroni, Marc, Silvia Bernardini, Adriano Ferraresi, \& Eros Zanchetta. 2009. The WaCky wide web: A collection of very large linguistically processed web-crawled corpora. Language Resources and Evaluation 43. 209-226.

Bender, Emily. 1999. Constituting context: Null objects in English recipes revisited. Penn Working Papers in Linguistics 6 (1). 53-68.

Bücking, Sebastian \& Jennifer Rau. 2013. German non-inflectional constructions as separate performatives. In Daniel Gutzmann \& Hans-Martin Gärtner (eds.), Expressives and Beyond. Explorations in Use-Conditional Meaning, 59-94. Leiden: Brill.

Culy, Christopher. 1996. Null object in English recipes. Language Variation and Change 8. 91-124. Fellbaum, Christiane \& Judy Kegl. 1989. Taxonomic structures and cross-category linking in the lexicon. Eastern States Conference on Linguistics. 6. 93-104.

Fillmore, Charles J. 1982. Frame Semantics. In Linguistic Society of Korea (ed.), Linguistics in the morning calm, 111-138. Seoul: Hanshin.

Fillmore, Charles J. 1985. Frames and the semantics of understanding. Quaderni di Semantica 6 (2). 222-254.

Fillmore, Charles J. 1986. Pragmatically controlled zero anaphora. Berkeley Linguistic Society (BLS) 12. 95-107.

Fitschen, Arne. 2004. Ein computerlinguistisches Lexikon als komplexes System. Stuttgart: Institut für Maschinelle Sprachverarbeitung der Universität Stuttgart dissertation.

Fries, Norbert. 1988. Über das Null-Topik im Deutschen. Forschungsprogramm Sprache und Pragmatik 3. 19-49.

Fraurud, Kari. 1996. Cognitive Ontology and NP Form. In Thorstein Fretheim \& Jeannette K. Gundel (eds.), Reference and referent accessibility, 65-67. Amsterdam \& Philadelphia: John Benjamins.

Goldberg, Adele E. 2006. Constructions at work. Oxford, UK: Oxford University Press.

Gundel, Jeanette K., Nancy Hedberg, \& Ron Zacharski. 1993. Cognitive status and the form of referring expressions in discourse. Language 69 (2). 274-307.

Günthner, Susanne. 2000. Creating scenic moments: grammatical and rhetoric-stylistic devices for staging past events in everyday narratives. Interaction and linguistic studies 22. 1-23.

Haegeman, Liliane. 1990. Understood subjects in English diaries: On the relevance of theoretical syntax for the study of register variation. Multilingua 9(2). 157-199.

Huang, C. 1984. On the distribution and reference of empty pronouns. Linguistic Inquiry 15. 531-574.

Krisjanis Karins, Robert MacIntyre, Monika Brandmair, Susanne Lauscher \& Cynthia McLemore. 1997. CALLHOME German Transcripts. LDC97T15. 
Koch, Peter \& Wulf Oesterreicher. 1985. Sprache der Nähe - Sprache der Distanz. Mündlichkeit und Schriftlichkeit im Spannungsfeld von Sprachtheorie und Sprachgeschichte (Langage de la proximité langage de la distance. L'oralité et la scripturalité entre la théorie linguistique et l'histoire de la langue). Romanistisches Jahrbuch 36. 15-43.

Lehrer, Adrienne. 1970. Verbs and Deletable Objects. Lingua 25. 227-253.

Michaelis, Laura A. 2011. Knowledge ascription by grammatical construction. In John Bengson \& Marc A. Moffett (eds.), Knowing How: Essays on Knowledge, Mind, and Action, 261-279. Oxford: Oxford University Press.

Mittwoch, Anita. 1982. On the difference between eating and eating something: Activities versus accomplishments. Linguistic Inquiry 13(1). 113-22.

Rehbein, Ines, Josef Ruppenhofer, Caroline Sporleder \& Manfred Pinkal. 2012. Adding nominal spice to SALSA-frame-semantic annotation of German nouns and verbs, In Jeremy Jancsary (ed.), 11th Conference on Natural Language Processing (KONVENS), 89-97. Vienna: ÖGAI.

Richling, Julia. 2008. Die Sprache in Foren und Newsgroups: eine Untersuchung der konzeptionellen Mündlichkeit und Schriftlichkeit im Wandel der Zeit. Saarbrücken: VDM Verlag.

Ruppenhofer, Josef. 2004. The interaction of valence and information structure. Berkeley, CA: University of California dissertation.

Ruppenhofer, Josef \& Laura A. Michaelis. 2010. A constructional account of genre-based argument omissions. Constructions and Frames 2(2). 158-184.

Schalowski, Sören. 2009. Uber Topik-Drop im Deutschen: Untersuchung zum Einfluss der grammatischen Funktion und des Merkmals Person. Berlin: Humboldt Universität zu Berlin Master's thesis.

Schlobinski, Peter. 2001. *knuddel - zurueckknuddel - dich ganzdollknuddel*. Inflektive und Inflektivkonstruktionen im Deutschen. Zeitschrift für Germanistische Linguistik 29(2). 192-218.

Schmid, Helmut. 1997. Probabilistic part-of-speech tagging using decision trees. In Daniel Jones \& Harold Somers (ed.), New methods in language processing, 154-164. London, UK: UCL Press.

Schwitalla, Johannes. 1988. Kommunikative Bedingungen für Ergänzungs-realisierungen. In Gerhard Helbig (ed.): Valenz, semantische Kasus und/oder "Szenen", 74-84. Berlin: Akademie der Wissenschaften.

Teuber, Oliver. 1998. fasel beschreib erwähn - Der Inflektiv als Wortform des Deutschen. Germanistische Linguistik 141/142. 6-26.

Zifonun, Gisela, Ludger Hoffmann \& Bruno Strecker. 1997. Grammatik der deutschen Sprache. Berlin \& New York: Walter de Gruyter. 